\title{
Inference of Reaction Kinetics for Supercritical Water Heavy Oil Upgrading with a Two-phase Stirred Reactor Model
}

\author{
Ashwin Raghavan ${ }^{1}$, Ping $\mathrm{He}^{2}$, and Ahmed Ghoniem ${ }^{1}$ \\ ${ }^{1}$ Massachusetts Institute of Technology \\ ${ }^{2}$ Lamar University
}

March 16, 2021

\begin{abstract}
We present the development and application of a two-phase stirred reactor model for heavy oil upgrading in the presence of supercritical water $(\mathrm{SCW})$, with coupled phase-specific thermolysis reaction kinetics and multicomponent hydrocarbon water phase equilibrium. We demonstrate the inference of oil and water phase kinetics parameters for a compact lumped reaction kinetics model through the application of this model to two different sets of batch reactor experiments reported in the literature. We infer that, though SCW can suppress the formation of newer polynuclear aromatics (PNA) from distillate range species, it is broadly ineffective in deterring the combination of pre-existing PNA fragments in the oil feed. Quantification of the conversion to distillate liquids before the onset of coke formation helps arrive at a clearer conclusion on whether the use of SCW in the batch reactor leads to better product outcomes for different oil feeds and operating conditions.
\end{abstract}

\section{Hosted file}

AIChE-21-23558_Proof_hi.pdf available at https://authorea.com/users/401980/articles/513905inference-of-reaction-kinetics-for-supercritical-water-heavy-oil-upgrading-with-a-twophase-stirred-reactor-model

\section{Hosted file}

main.tex available at https://authorea.com/users/401980/articles/513905-inference-ofreaction-kinetics-for-supercritical-water-heavy-oil-upgrading-with-a-two-phase-stirredreactor-model 

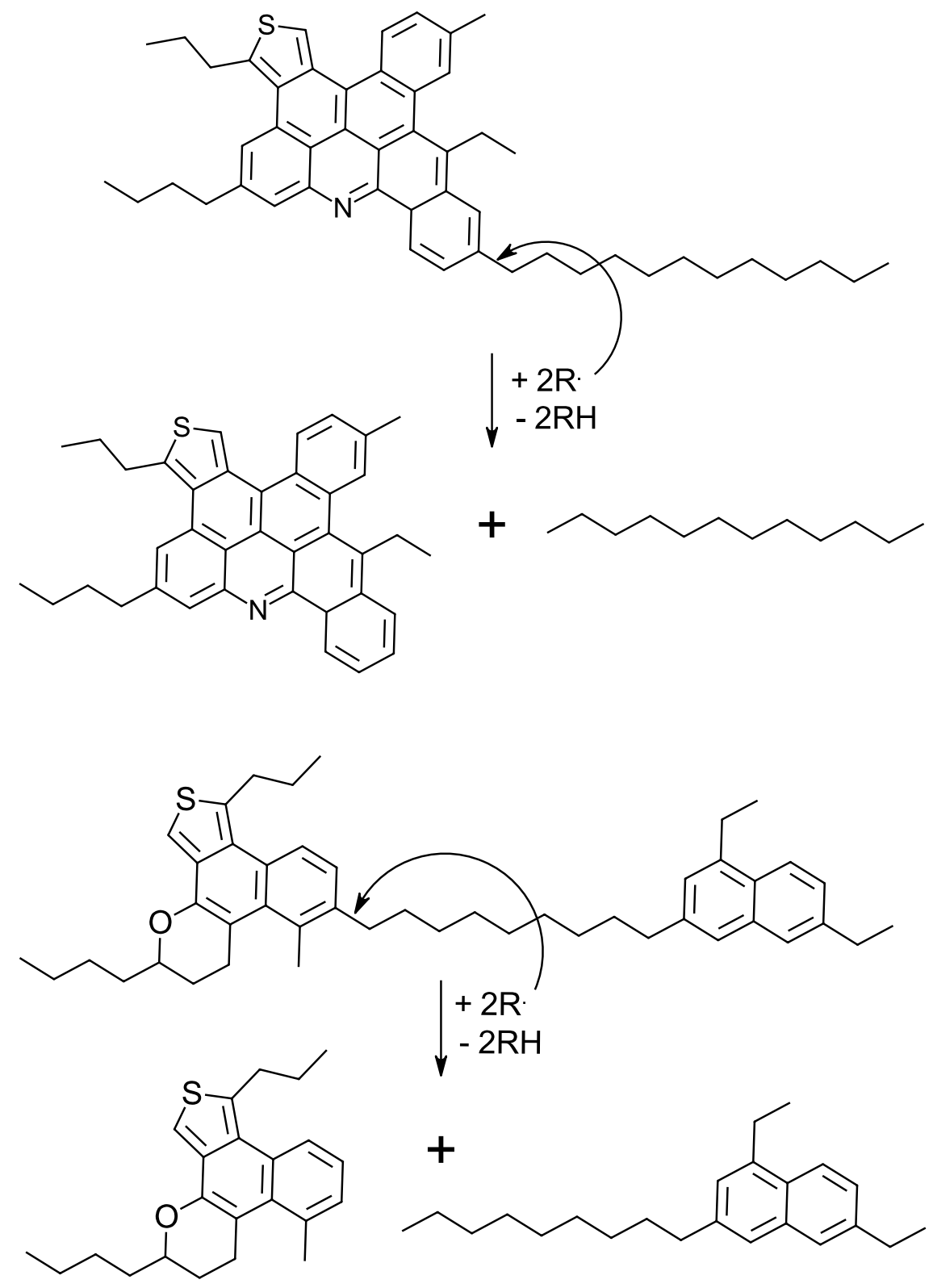


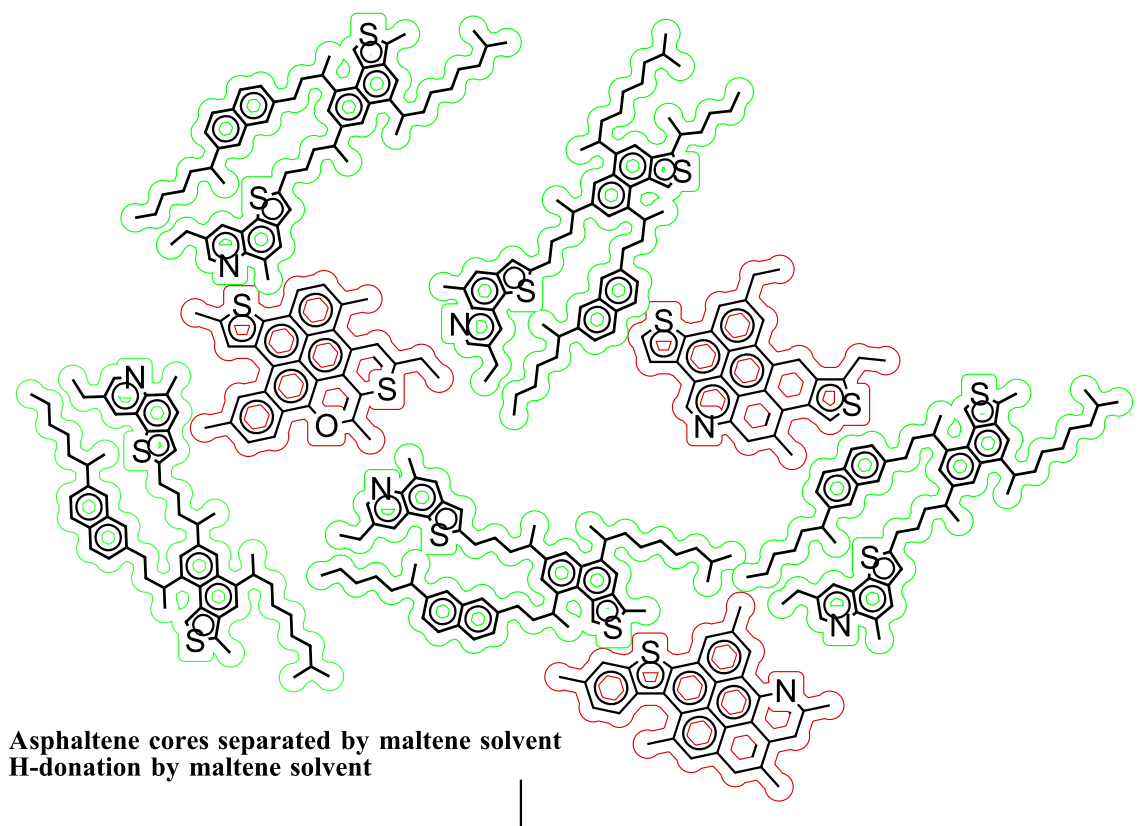

Phase Separation
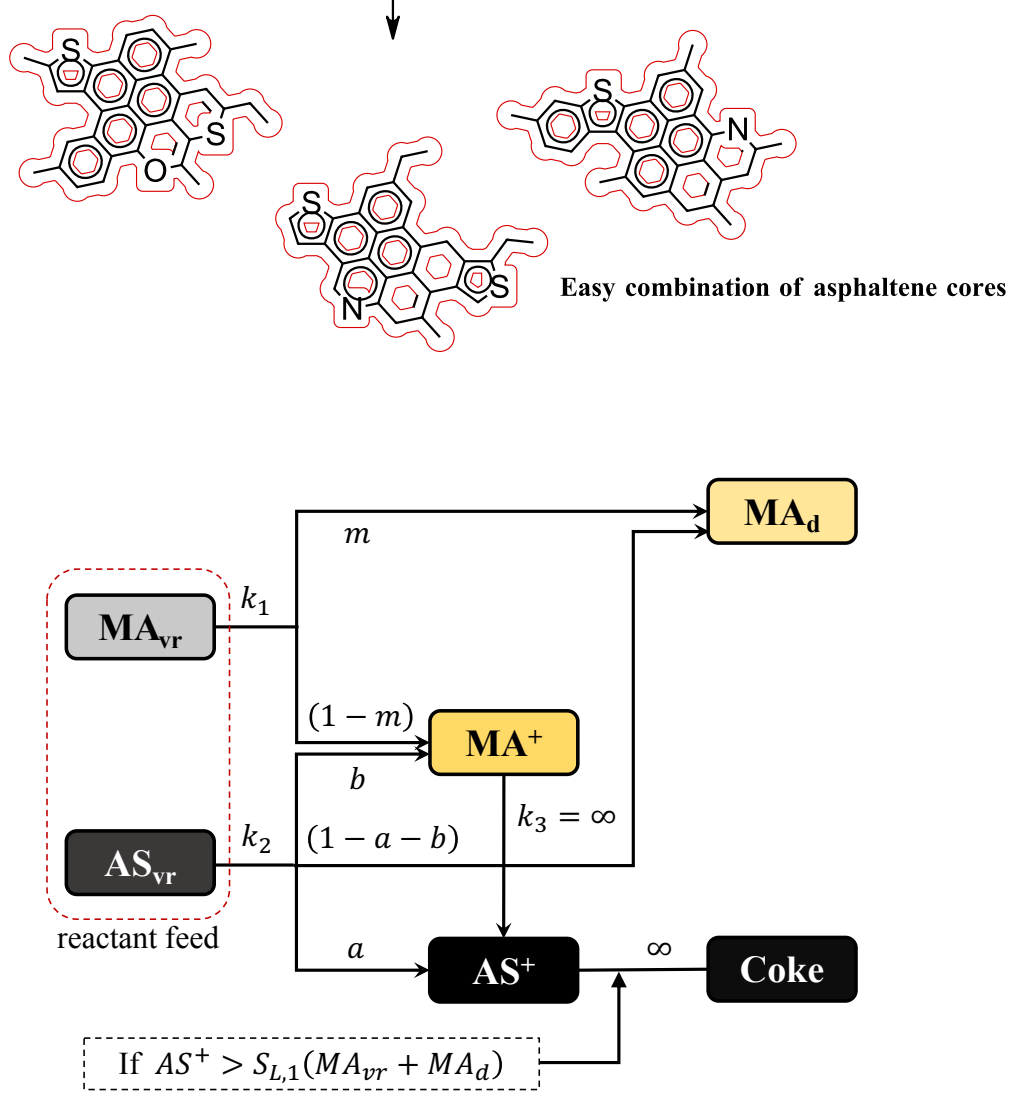

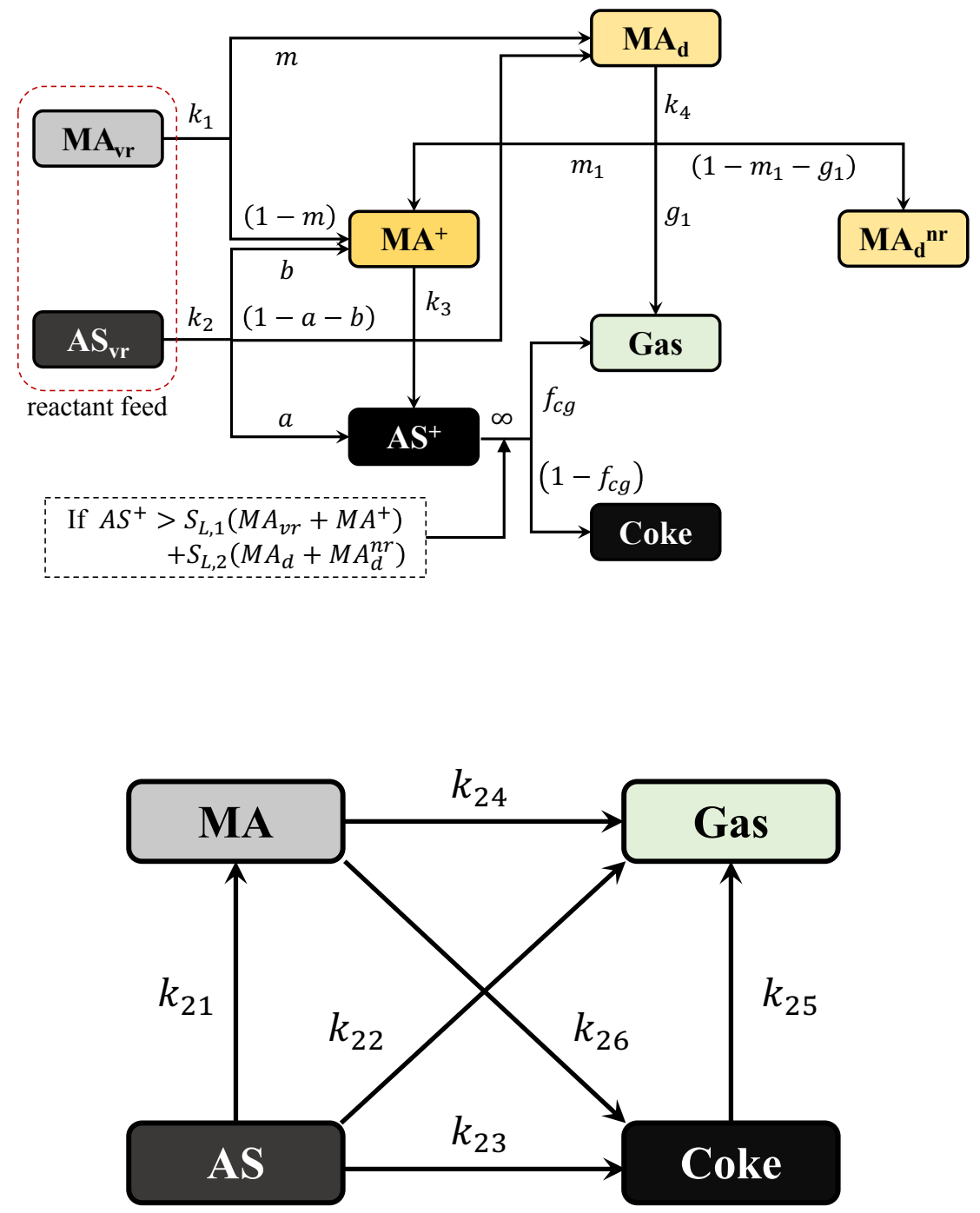


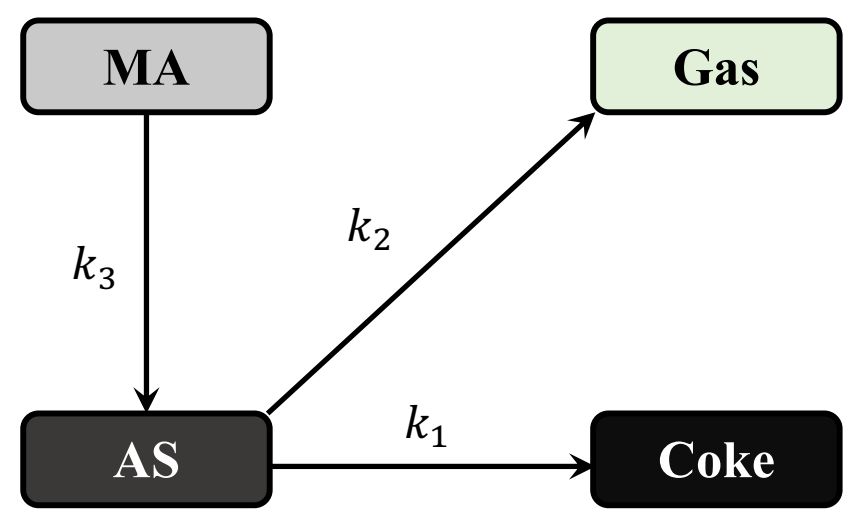




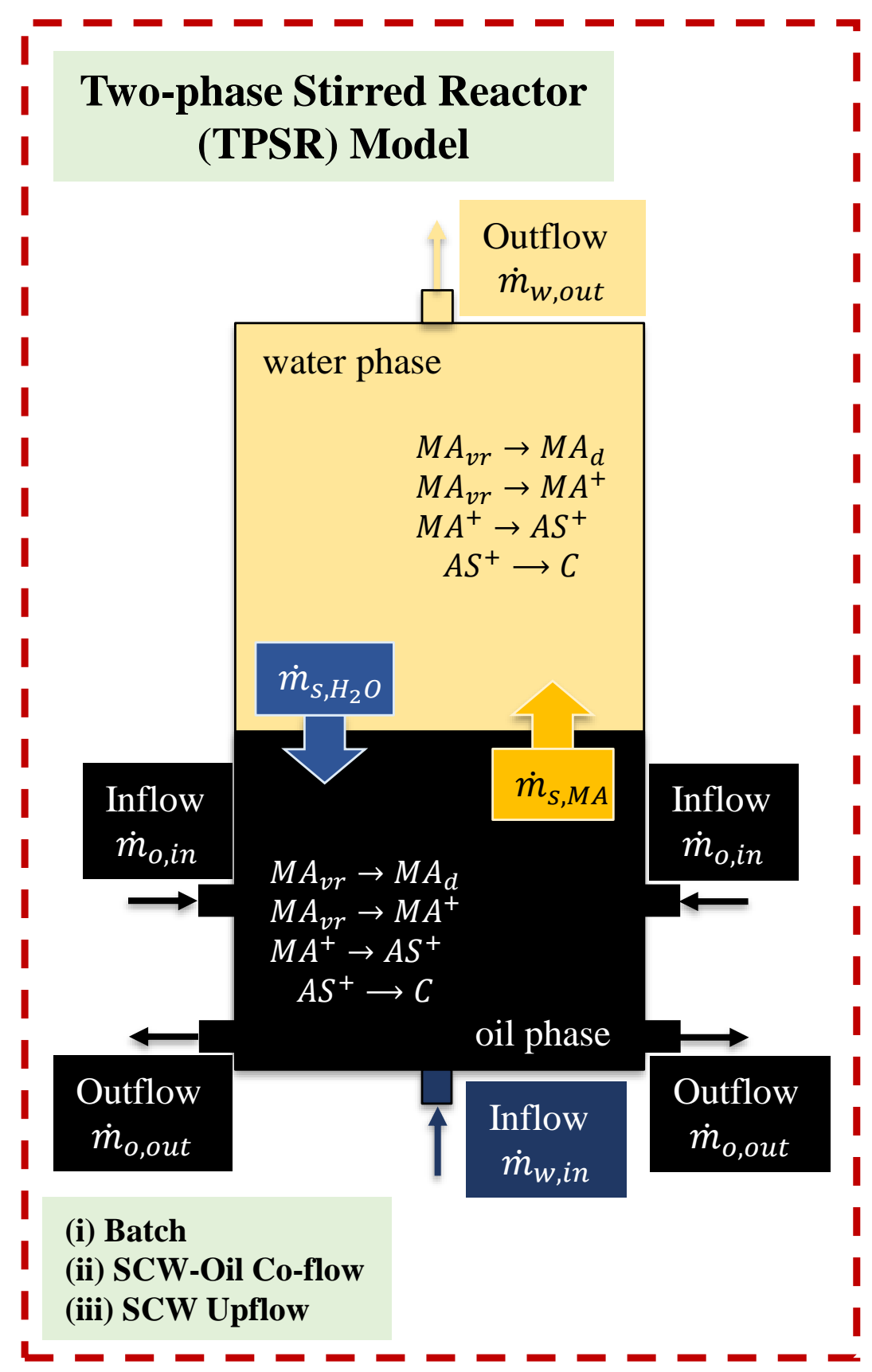



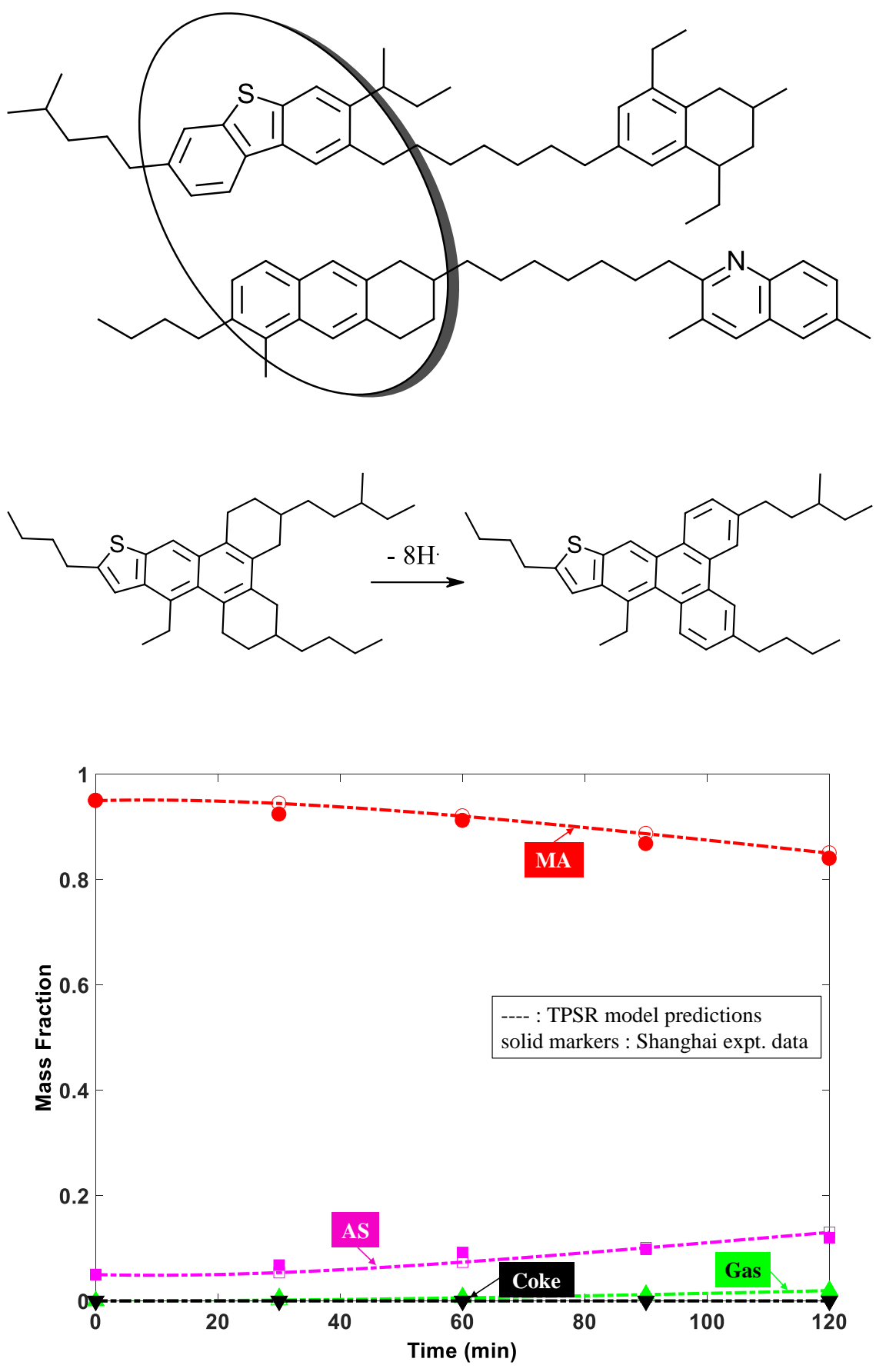

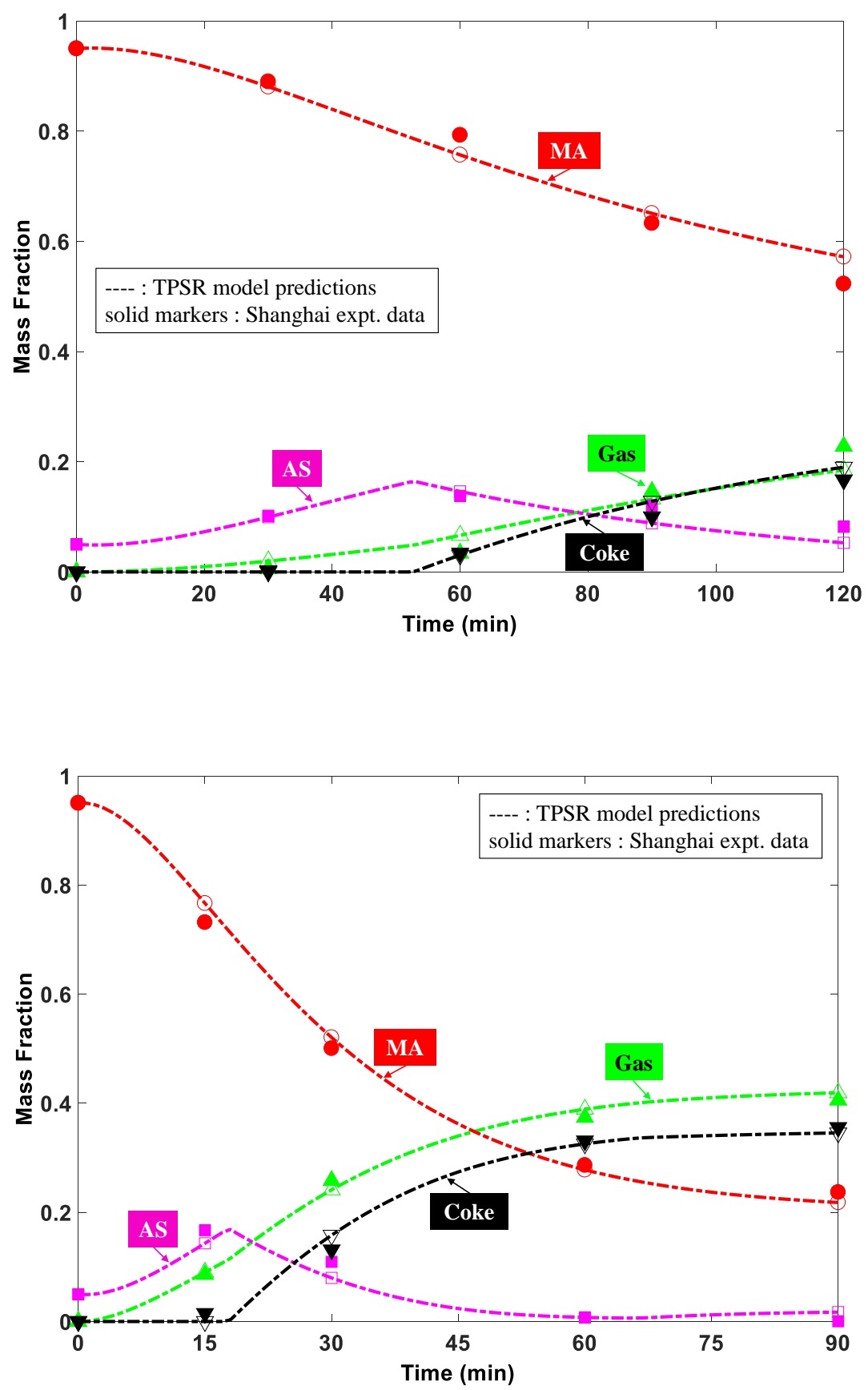

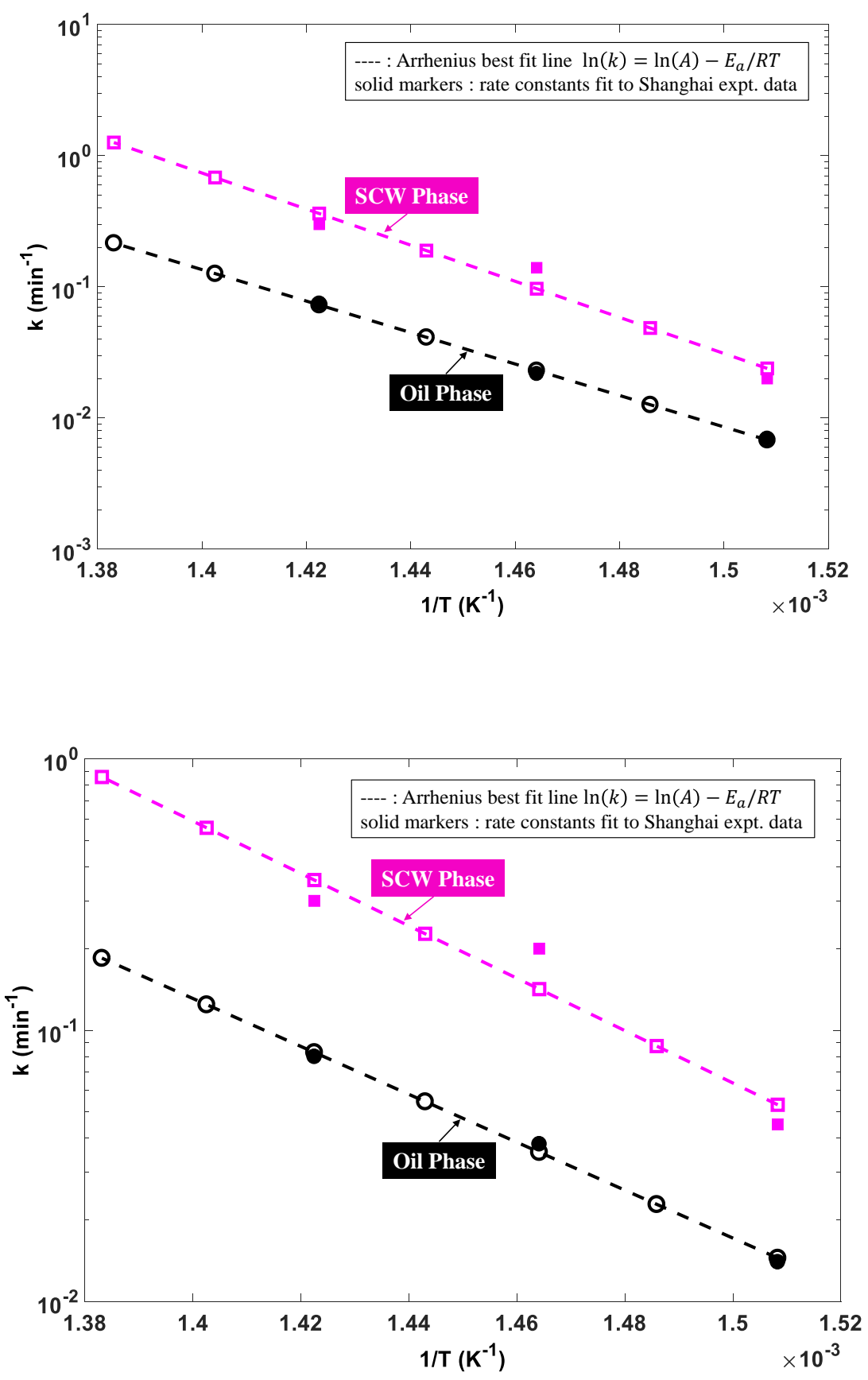

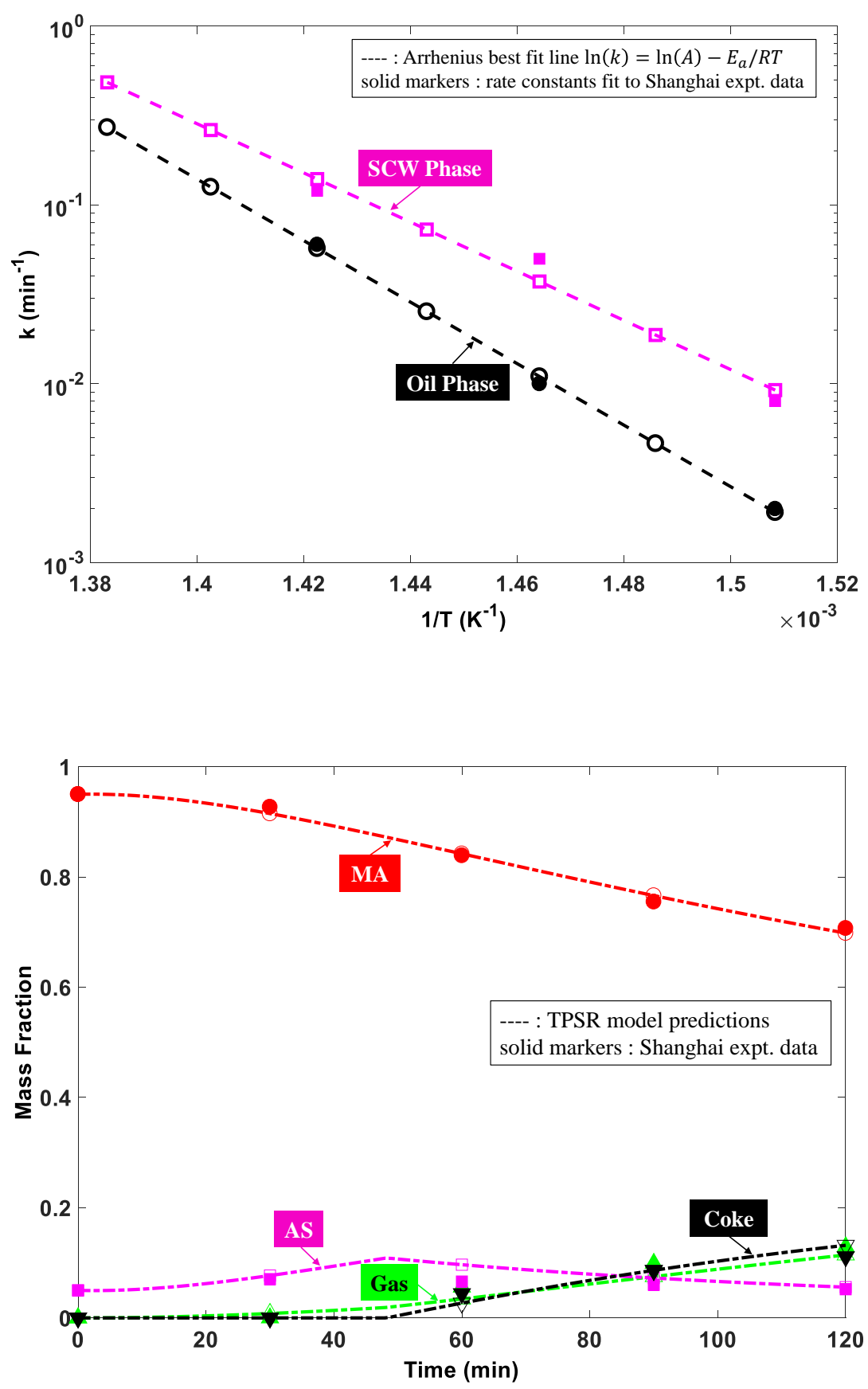

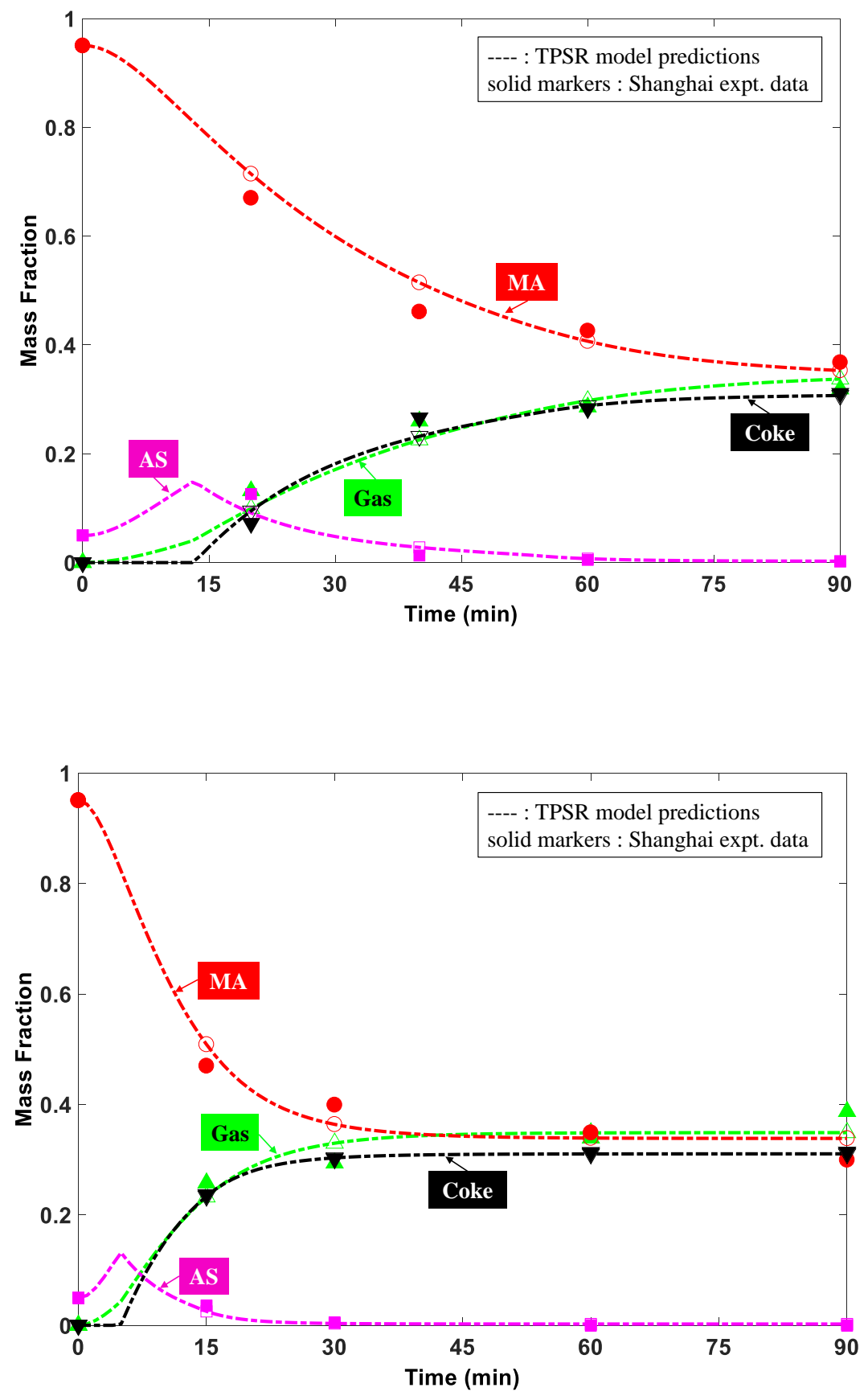

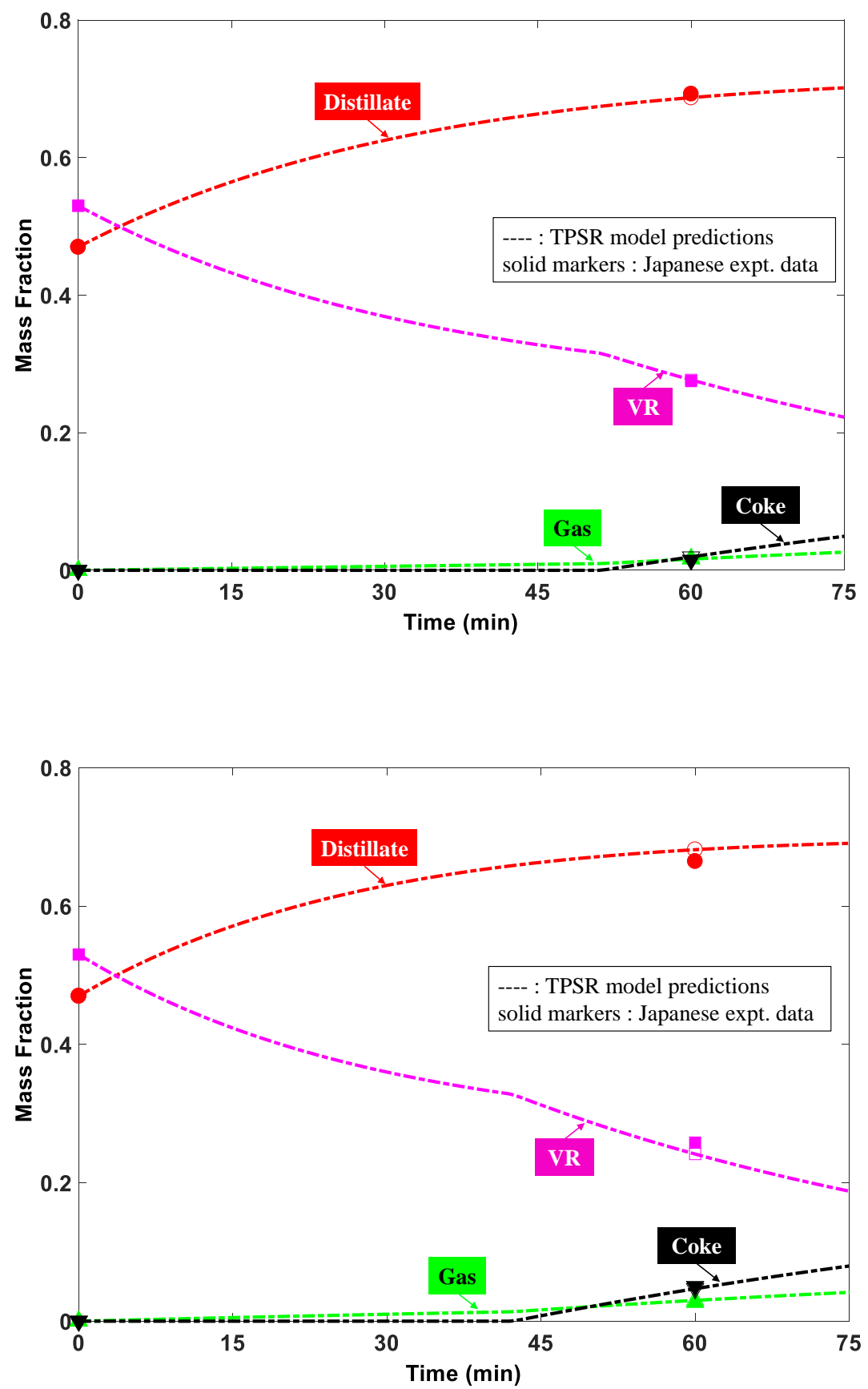

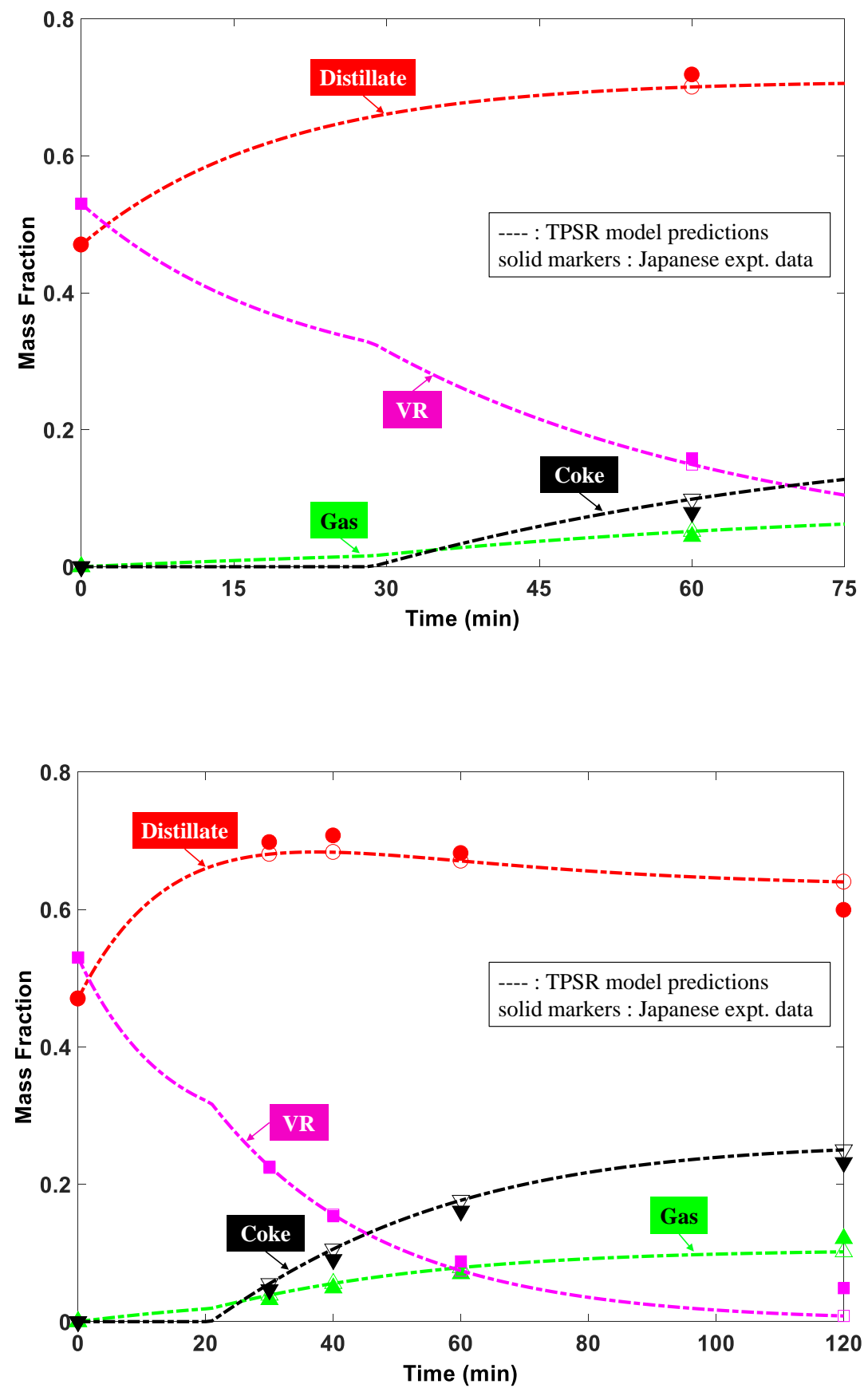

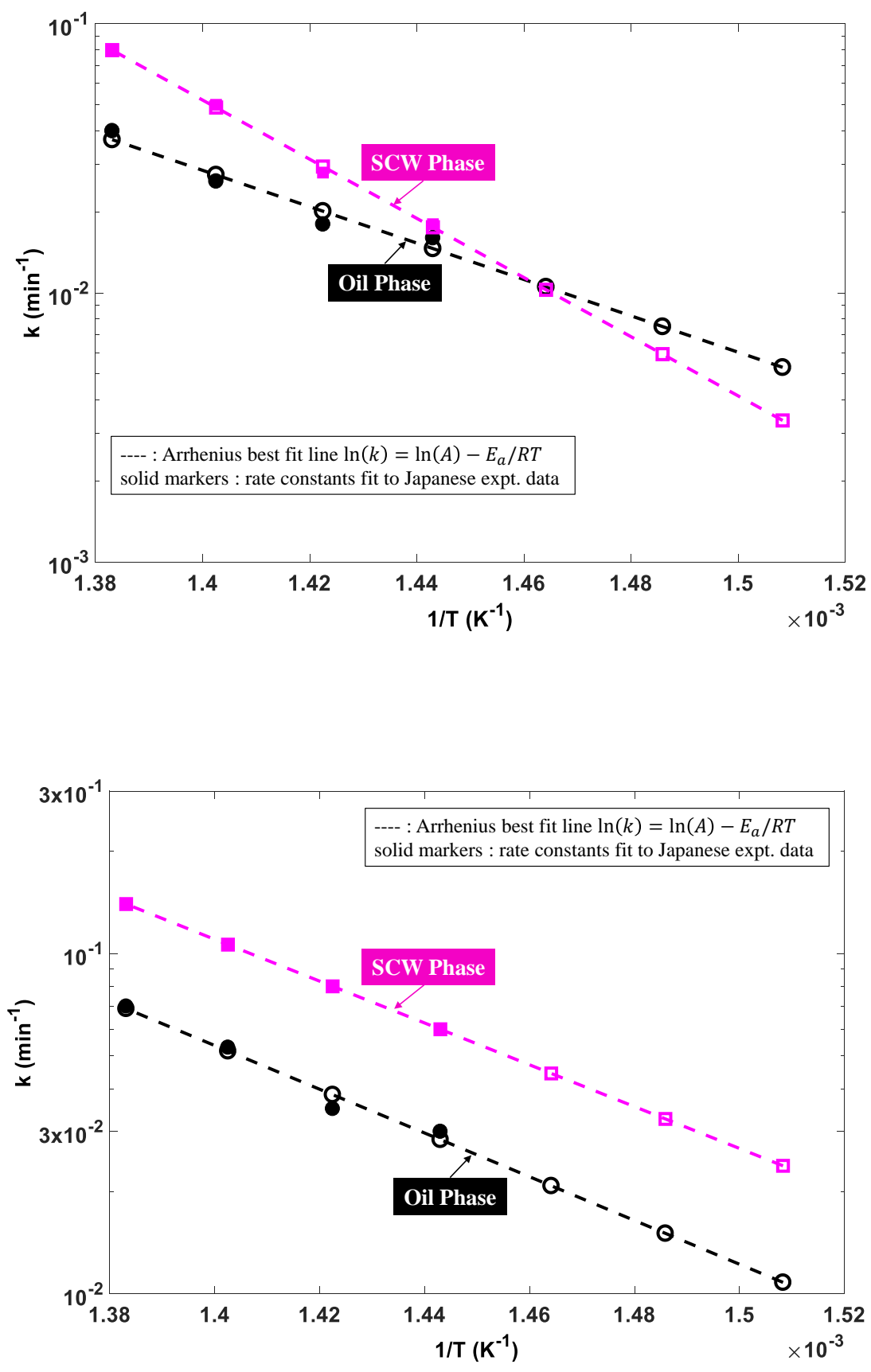

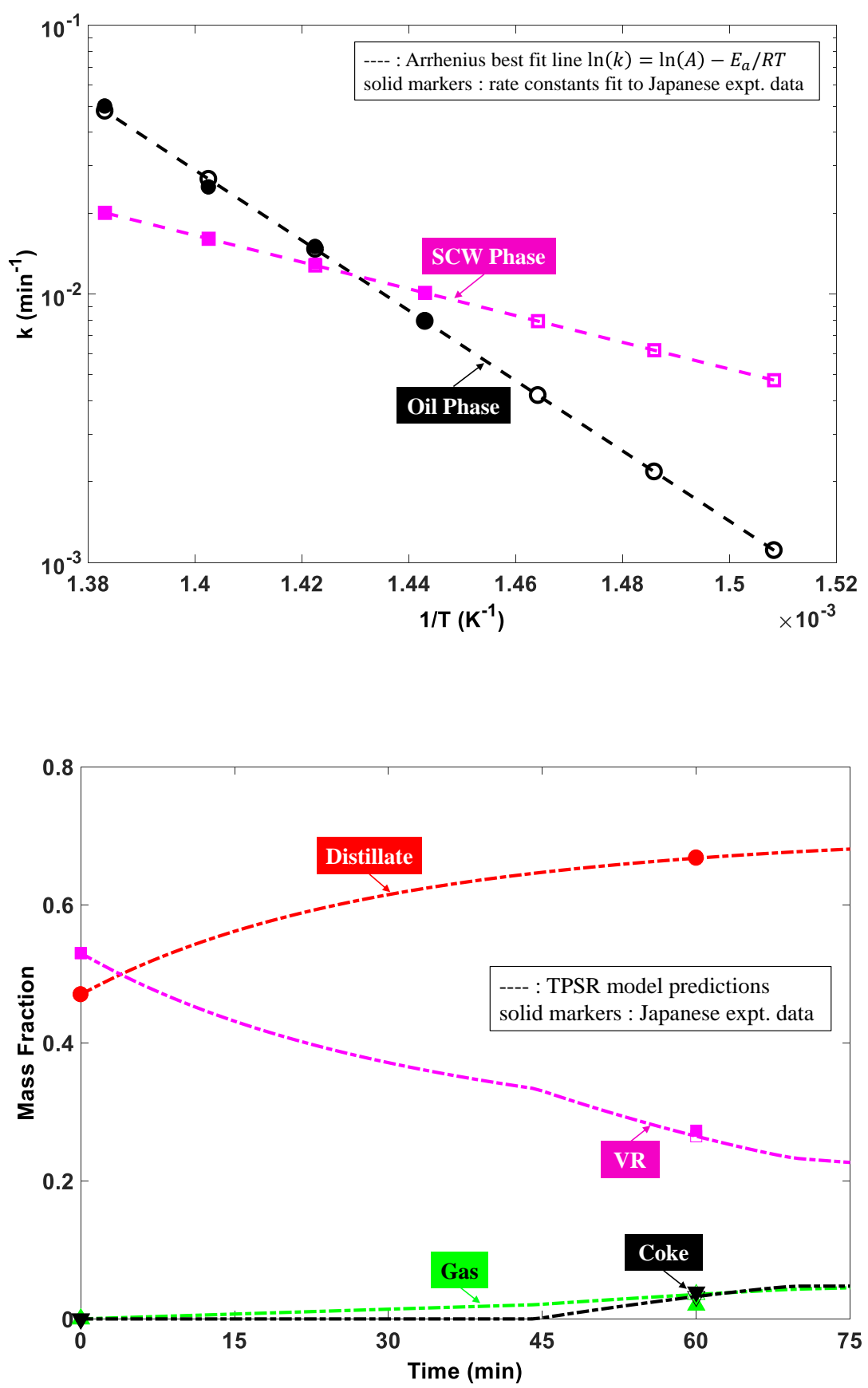

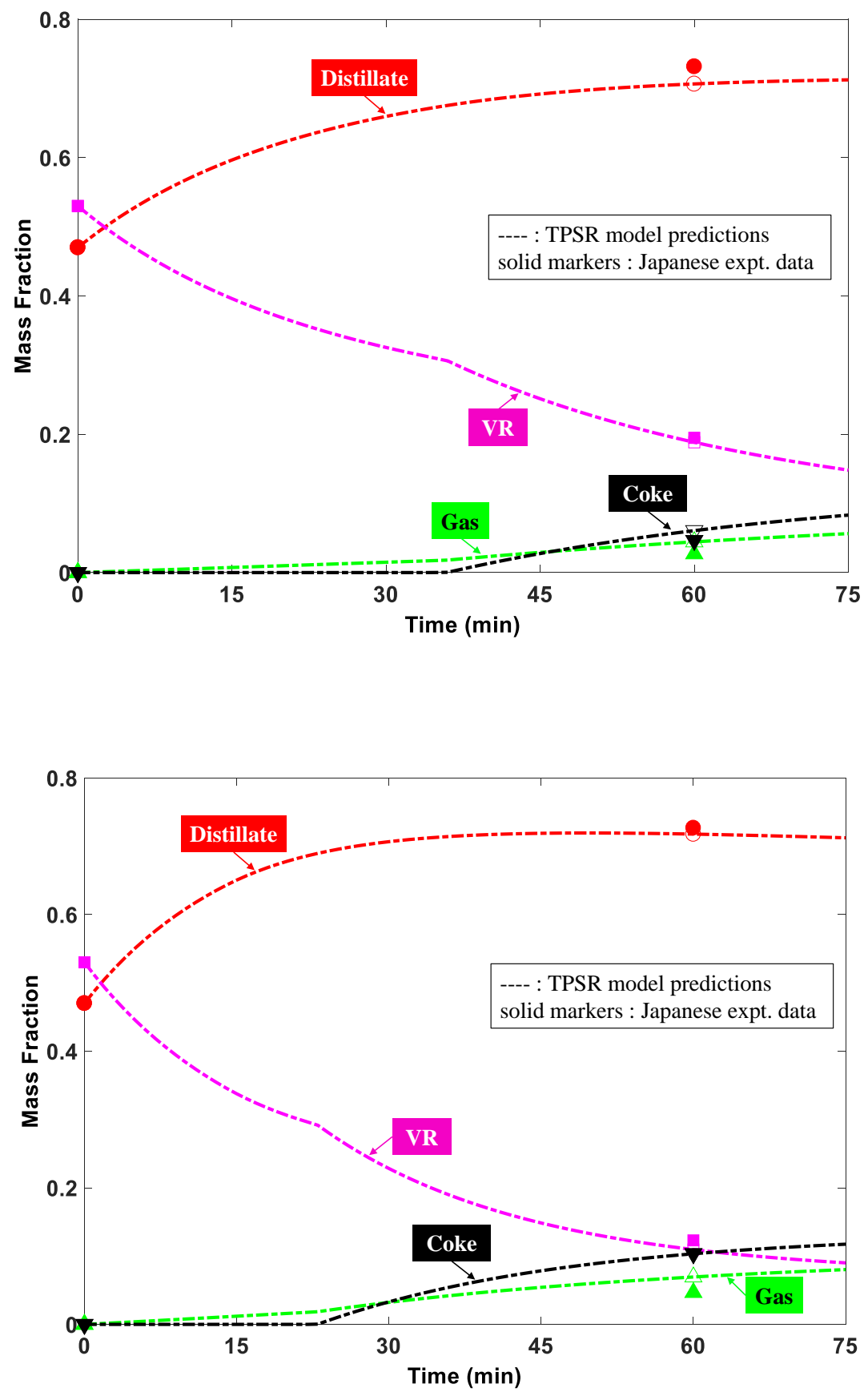


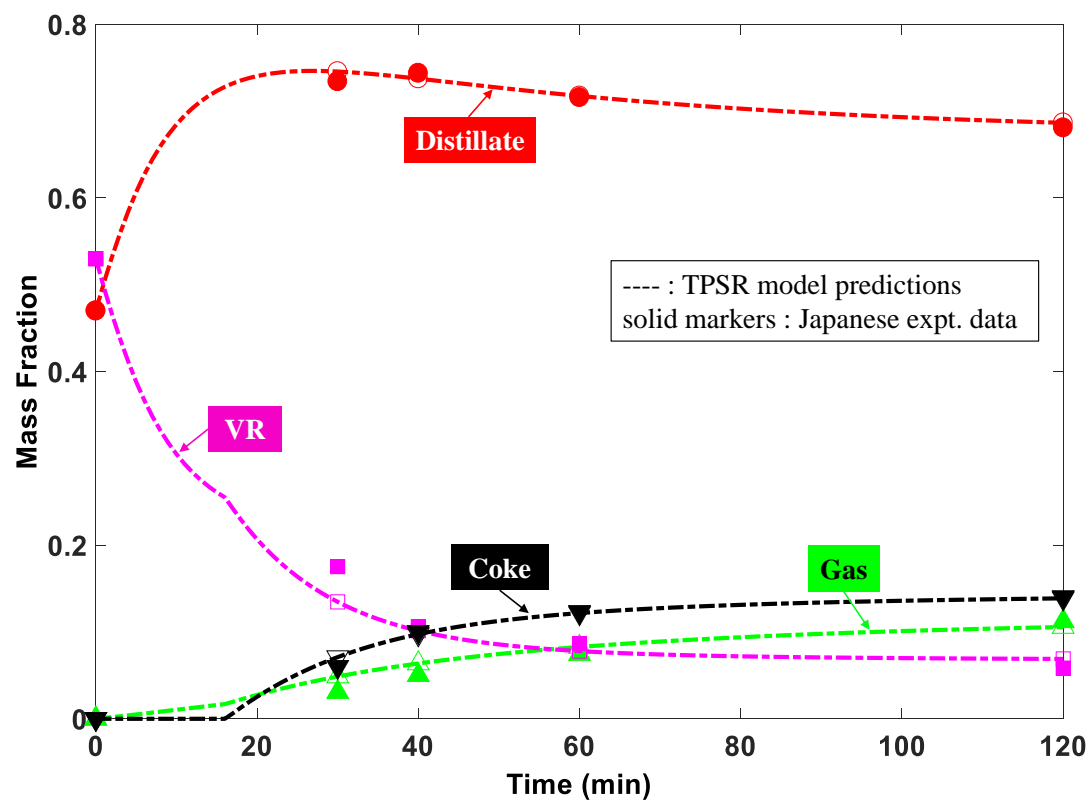

